\title{
Impact of Gatorade Beverage on Elite Female Badminton Players' Performance
}

\author{
Sepideh Mehraein \\ Faculty of Educational Studies \\ Universiti Putra Malaysia (UPM), Malaysia \\ sepideh20_k@yahoo.com (Correspondece author) \\ Kaveh Khabiri \\ Faculty of Humanities, \\ Islamic Azad University of Ashtian, Arak, Iran \\ sepka_kh@yahoo.com \\ Mohammad Reza Pouria \\ President of Badminton Federation Islamic Republic, Iran \\ Mohamadrezapouria@gmail.com \\ Arash Rashidi \\ Faculty of Nutrition Sciences and Food Technology \\ Shahid Beheshti University of Medical Sciences, Tehran, Iran \\ a.rashidi@nnftri.ac.ir \\ Majid Hajifaraji \\ Dept. of Nutrition and Food Policy \& Planning Research \\ Shahid Beheshti University of Medical Sciences, Tehran, Iran \\ M.hajifaraji@nnftri.ac.ir
}

\begin{abstract}
Sports beverages assumed as one the principle factor on players' performance, and impact on their indicators, noticeably. Gatorade beverage is one of this primary beverages that in present study focused on its impact on elite female badminton players' performance in Iran. In the present survey has been considered in 2 groups of Gatorade and control that included 79 participants. The data has been got based on 24 hours' recall questionnaire on three different days in every week. As well, skin folds' brachial triceps index was applied for body fat percent assessment. To quantity VO2max, Shuttle runs sub-maximal test was used. Also, for controlling fluid intake in every two groups based on players' body weight, $150 \mathrm{ml}$ per every $70 \mathrm{~kg}$ weight for every 15 minutes was recommended. Besides, for control of blood volume changes related to plasma blood glucose, hematocrit, hemoglobin, sodium, and potassium was measured during three time periods of zero, 30 minutes after the start and 90 minutes after the start. To end, to measure performance, standardized tests measure the indicators: aerobic power, speed, flexibilityy, agility, muscular strength, and endurance were used. The results showed that supply adequate water and fluids in during of sport, play a critical role in gaining the high level of female badminton players' performance. In truth, the players who supply enough water shown better performance as compared with those who provide Gatorade beverage.
\end{abstract}

Keywords: Badminton, Elite Female, Gatorade, Iran, Players, Sport Beverages. 


\section{Introduction}

At present, diet planning and supplying nutrients besides of regular exercise have a considerable role in increasing players' performance (Bailey et al., 2009). Sports beverages have considered more by players, and also they have a good market at most of the sports clubs (Zytnick, Park, \& Onufrak,2015). In recent years, this growth in Asia, America, and Europe amongst players has been remarkable (Global Sports Drinks Report Comprehensive Analysis of Trends in the Global Sports Drinks Market Including Long-term Forecasts,"2014; Zenith International). The sports beverages usually have been used before, during, and after of exercise, but their impacts on physiological and psychological indicators more challenges. There are several studies regarding the effect of sports beverages on players' performance; also, some of them recommended their positive impacts in recovery time (Fahlström, Fahlström, \& Lorentzon, 2006). But should be considered the sports beverages are dissimilar with energetic beverages; also, should know the sports beverages are effective and increase the level of players' performance (Kumar, Park, \& Onufrak, 2015).

According to the important role of sports beverages, there is a few research that focused on sports beverages that influence on players' performance based on indicators. Furthermore, in the current study examined the impact of Gatorade beverages and water with diet planning on elite female badminton players' performance in Iran. (the sports beverages included 1) water, 2) glucose, fructose, maltodextrin or a combination of 3 electrolytes, including sodium, potassium, phosphorus, chlorine and other compounds necessary for the use of players before, during and after sports activities) (Urdampilleta et al., 2015). In this study assumed that supplying Gatorade beverage based on indicators: aerobic power, speed, flexibility, agility, muscular strength, and endurance during eight weeks are affectless.

\section{Role of Sports Beverages on Players Performance}

Supplying water and liquid has a considerable contribution to preventing the low level of players' performance, because these beverages can compensate the lack of water that lost in during of playing and exercise, rapidly. This fact should be encouraged by trainers because players usually do not have any tendency to drink liquid unless they feel thirsty (Neal, Corbett, Massey, \& Tipton, 2015). If supplying liquids controlled by players, there is not any health problem and they could be useful (Hamouti, Fernández-Elías, Ortega, \& MoraRodriguez,2014).

Sports beverages have been used more than one decade by players, but there are not adequate studies about their advantages and disadvantages in a long time. Lack of attention to these facts appeared numerous difficulties in activities and outcomes of players. Nowadays, the sports beverages designed for two purposes. The first one is taste and prevention of dehydration, and the second one is supplying carbohydrate for replacing electrolyte excretion through sweat. Additionally, the carbohydrate beverages divided into two groups: 1) carbohydrate with high density (more than 10\%), and 2) carbohydrate with low density (less than 10\%) (Logan-Sprenger, Heigenhauser, Jones, \& Spriet, 2015). In this study examined the second type.

In this regard, Larson, DeWolfe, Story, and Neumark-Sztainer (2014) examined using sports beverages with energetic beverages. The researchers focused on 2793 girl students; they 
explained that one-third of participants consumed sports beverages at least once a week. The consumer group illustrated the high level of performance as compared with others. In the same vein, Pérez-Idárraga and Aragón-Vargas (2014) explained that sports beverages prevent to body dehydration and also they have an effective role on a high level of performance. Similarly, Peltier et al. (2013) emphasized on the influence of sports beverages before exercise in recovery; and also, they explained about stamina on tennis players' performance in similar circumstances competition. In this study, the researchers were not sure about effectiveness of sports beverages. In (2012), Abián-Vicén, Del Coso, González-Millán, Salinero, and Abián considered on 70 players (male-female). They reported players supplied dehydration via water and sports beverages, but these researchers did not explain that the sports beverages improve their performance or by drinking water.

In Iran, Kazemi, Gaieny, andKordi (2000) focused on the effect of sports beverages on the performance of athletes. The researchers described that using sports beverages such as Fantom and Deragon has an ergogenic impact on endurance performance amongst 12 girl students. Additionally, Gaieny, Sattari Fard, and Rezaie (2012) explained that Redbol and Hype have an ergogenic influence on endurance performance of players.

Regarding the critical role of nutrition of players and sport society requirements to using supplements, and also lack studies in this area, the researchers endeavor to examine sports beverages using and their impacts on elite female badminton players' performance in Iran.

\section{Methodology}

Overview

In the present study has been used semi - experimental controlled study, and 79 elite female badminton players between 20-26 years old were randomly selected. The participants of the survey have been divided into two groups as follows: Gatorade group ( $\mathrm{Ga}$ ) and control group (Co).

\section{Measurement}

The measurements of the present survey comprised: first, the 24 hours' recall questionnaire had completed in 3 different days in every week (during the 8-week period). The macronutrient and energy intake was measured. Second, The skin folds' brachial triceps index was used for body fat percent assessment. Third, To measure VO2max, Shuttle runs sub-maximal test was used. Fourth, for controlling fluid intake in every three groups based on an athlete's body weight, $150 \mathrm{ml}$ per every $70 \mathrm{~kg}$ weight for every 15 minutes was recommended. Fifth, for control of blood volume changes related to plasma blood glucose, hematocrit, hemoglobin, sodium, and potassium was measured during three time periods of zero, 30 minutes after the start and 90 minutes after the start. Sixth, to provide the same pressure conditions in practice, the average pressure of exercises for each group over the eight weeks on the scale mileage was included using a pedometer. Three indicators understand or feel the pressure, stomach fullness and thirst scale were assessed. Seventh, to measure performance, standardized tests measure the indicators: aerobic power, speed, flexibility, agility, muscular strength, and endurance were used. In Gatorade group that has been focused in the present study, used Gatorade sports beverage. 


\section{Data Analysis}

The current research has been used descriptive statistics, Gabriel's post hoc test, and paired ttest to examine the differences within the group via SPSS version 20 statistical software.

\section{Results}

Table 1 revealed that the Mean of oxygen consumption amongst two groups of Gatorades and control is significant $(F(1,77)=6.79, p<.01)$. Regarding Gabriel's post hoc test, there is a meaningful difference between Gatorade and control group $(p=0.041)$. The results in the paired t-test showed that there is no significant difference between in Gatorade's group ( $p=$ $0.057)$, but there is a meaningful difference in the control group $(p=0.034)$. As well, the results revealed that there is no significant difference in changes Mean of speed amongst two groups Gatorades and control $(F(1,77)=3.09, p=0.055)$. In the paired t-test likewise did not observe any difference between Gatorade group $(p=0.21)$ and control group $(p=0.19)$. The finding exposed that there is no significant difference in changes Mean of flexibility amongst two groups Gatorades and control $(F(1,77)=6.14, p=0.061)$. In the paired t-test observed difference between Gatorade group $(p=0.022)$ and control group $(p=0.036)$. Additionally, Table 1 displayed that there is no significant difference in changes Mean of agility amongst two groups Gatorades and control $(F(1,77)=2.05, p=0.11)$. Also, in the paired t-test observed difference between Gatorade group $(p=0.046)$ and control group $(p=0.035)$. Likewise, the changes Mean of aerobic power is not significant amongst two groups Gatorades and control $(F(1,77)=7.16, p=0.056)$. Further, in the paired t-test there is no difference between Gatorade group $(p=0.08)$, but there is a meaningful difference in the control group $(p=0.029)$. The results in Table 1 released that the changes Mean of muscular strength is not significant amongst two groups Gatorades and control $(F(1,77)=4.11, p=$ $0.17)$. In the paired t-test there is no difference between Gatorade group ( $p=0.092)$, but there is a meaningful difference in the control group $(p=0.018)$. What the changes Mean of upper limb muscle endurance is not significant amongst two groups Gatorades and control $(F(1$, $77)=5.52, p=0.068$ ). In the paired t-test there is difference between Gatorade group $(p=$ 0.022 ) and control group ( $p=0.031)$. The changes Mean of abdominal muscle endurance is not significant amongst two groups Gatorades and control $(F(1,77)=4.31, p=0.073)$. In the paired t-test there is no difference in Gatorades group $(p=0.059)$, but there is a meaningful difference in the control group ( $p=0.038)$. 
Journal of Educational, Health and Community Psychology

Vol 6, No 2, 2017. E-ISSN 2460-8467

Mehraein, Khabiri, Pouria, Rashidi, Hajifaraji

Table 1 .

Changes between group and among group of indicators

\begin{tabular}{|c|c|c|c|c|c|c|c|}
\hline \multirow[b]{2}{*}{ Indicators } & \multirow[b]{2}{*}{ Groups } & \multicolumn{2}{|c|}{$\mathrm{SD}$} & \multirow[b]{2}{*}{$F$} & \multirow[b]{2}{*}{$p$} & \multirow[b]{2}{*}{$t$} & \multirow[b]{2}{*}{$p$} \\
\hline & & Pretest & Posttest & & & & \\
\hline \multirow{2}{*}{$\begin{array}{l}\text { Oxygen } \\
\text { consumption }\end{array}$} & Ga: $n=39$ & $45.1 \pm 2.2$ & $46.5 \pm 2.1$ & 6.79 & 0.011 & 1.94 & 0.057 \\
\hline & Co: $n=40$ & $43.1 \pm 1.9$ & $45.4 \pm 2.3$ & & & 3.02 & 0.034 \\
\hline \multirow[t]{2}{*}{ Speed } & Ga: $n=39$ & $0.92 \pm 0.05$ & $0.94 \pm 0.04$ & 3.09 & 0.055 & 1.86 & 0.21 \\
\hline & Co: $n=40$ & $0.92 \pm 0.02$ & $0.93 \pm 0.03$ & & & 1.30 & 0.19 \\
\hline \multirow[t]{2}{*}{ Flexibility } & Ga: $n=39$ & $175 \pm 7$ & $177 \pm 7$ & 6.14 & 0.061 & 2.80 & 0.022 \\
\hline & Co: $n=40$ & $174 \pm 6$ & $179 \pm 7$ & & & 2.01 & 0.036 \\
\hline \multirow[t]{2}{*}{ Agility } & Ga: $n=39$ & $11.8 \pm 0.3$ & $10.04 \pm 5.3$ & 2.05 & 0.11 & 1.23 & 0.046 \\
\hline & Co: $n=40$ & $12.1 \pm 0.4$ & $10.05 \pm 7$ & & & 2.03 & 0.035 \\
\hline \multirow[t]{2}{*}{ Aerobic power } & Ga: $n=39$ & $59.2 \pm 4.1$ & $60.0 \pm 3.0$ & 7.16 & 0.056 & -4.01 & 0.08 \\
\hline & Co: $n=40$ & $59.2 \pm 4.2$ & $63.2 \pm 6.3$ & & & -5.33 & 0.029 \\
\hline \multirow{2}{*}{$\begin{array}{l}\text { Muscular } \\
\text { strength }\end{array}$} & Ga: $n=39$ & $37.8 \pm 2.8$ & $37.3 \pm 2.6$ & 4.11 & 0.17 & 1.09 & 0.092 \\
\hline & Co: $n=40$ & $38.2 \pm 3.6$ & $38.9 \pm 4.1$ & & & -2.97 & 0.018 \\
\hline \multirow{2}{*}{$\begin{array}{l}\text { Upper limb } \\
\text { muscle } \\
\text { endurance }\end{array}$} & Ga: $n=39$ & $26 \pm 5$ & $31 \pm 6$ & 5.52 & 0.068 & 3.12 & 0.022 \\
\hline & Co: $n=40$ & $27 \pm 3$ & $31 \pm 4$ & & & 1.91 & 0.031 \\
\hline \multirow{2}{*}{$\begin{array}{l}\text { Abdominal } \\
\text { muscle } \\
\text { endurance }\end{array}$} & Ga: $n=39$ & $55 \pm 4$ & $55 \pm 4$ & 4.31 & 0.073 & -1.96 & 0.059 \\
\hline & Co: $n=40$ & $58 \pm 6$ & $55 \pm 8$ & & & -2.70 & 0.038 \\
\hline
\end{tabular}

\section{Discussion}

Concerning to the results of the present study and the meaningful role of sports beverages in players' efficiency; in this survey, examined the impact of sports beverage on elite female badminton players' performance in Iran (without any recommendation for selecting and using beverage). Based on the results of the study, it seems that water consumption has a considerable impact on increasing of oxygen consumption as compared with Gatorade. The findings of the present study showed that those who are consuming water enough illustrated the high level of performance and activity in during of their exercise and competitions.

On the other hand, there is no significance in changes Mean of flexibility amongst two groups Gatorades and control. In fact, the flexibility assumed as the main indicator in Badminton (Chen, Mok, Lee, \& Lam, 2015). While there is meaningful difference between Gatorade and control group in changes Mean of agility, these results are corresponding with the research of Zytnick et al. (2015), Coso, Estevez, Baquero, \& Mora-Rodriguez (2008),Abián-Vicén, Del Coso, González-Millán, Salinero, \&Abián(2012), and Perez and Aragón-Vargas (2014); 
while the findings are not same with the research ofUrdampellita et al. (2015). It seems that this dissimilarity is because of short time consuming of sports beverage and doing hard exercises.

Regarding to the revealed results based on meaningful difference in Gatorade and control group in aerobic and not significant difference in Gatorade and control group in muscular strength, the studies of Larson et al. (2014), Chen et al. (2015), PerezandAragón-Vargas (2014), and Gaieny et al. (2012) are in parallel with the study.

In addition, based on the results of the changes Mean of upper limb muscle endurance and abdominal muscle endurance, the surveys of Larson et al. (2014), Chen et al. (2015),Samavati Sharif, Hojatti, Vojdani, and KashrafiFard(2013), and Kazemi et al. (2010) are in parallel of this research, while the results are not similar to the studies of Peltier et al. (2013) and Labotz, Harris, and Anderson (2009).

\section{Limitations}

The main limitation of the current study is related to the population of the research. The study just limited to professional sport and not representative of the population of badminton athletes in the country; and also, it just restricted to female and not both sex (female and male) of badminton athletes.

\section{Suggestions}

\section{Executive Suggestions}

According to the findings, consuming energy and nutrition's food have a considerable role in improving athlete performance; in this regard, the trainers and supervisors have meaningful roles in encouraging athletes to consuming natural beverage and food and changing athletes' attitude toward sports beverage. Furthermore, recommended the trainers and supervisors determine specific nutrition framework and conduct athletes based on it.

\section{Research Suggestion}

The study considered on female population, for the future research, recommended focused on the same age groups in men in all sports fields, especially whole sports that included endurance and strength. Additionally, suggested, in the future studies examine participants in a long period, and compared consumption of some beverages with energetic beverages. Due to inadequate knowledge of athletes, recommended will be examined more research in education and improving behavioral patterns athletes' area. 


\section{Conclusion}

According to the performance indicators and their results, the main factor in increasing elite female badminton players' performance is a supply of adequate water and liquids during of exercises and also controlling carbohydrates, protein, and fat. In comparing of the control group and Gatorades group, those one consuming water shown a high level of performance as compared with Gatorade group. These factors should be considered by trainers and sports federation till observing better result from players in sports society.

\section{References}

Abián-Vicén, J., Del Coso, J., González-Millán, C., Salinero, J. J, \&Abián, P. (2012). Analysis of dehydration and strength in elite badminton players, PLoS ONE, 7(5), e37821. doi: 10.1371/journal.pone.0037821.

Bailey, S. J., Winyard, P., Vanhatalo, A., Blackwell, J. R., Dimenna, F. J., Wilkerson, D. P., ... Jones, A. M. (2009). Dietary nitrate supplementation reduces the O2 cost of low intensity exercise and enhances tolerance to high - intensity exercise in humans. $J$ ApplPhysiol, 107, 1144 - 1155.

Chen, B., Mok, D., Lee, W. C. C., \& Lam W. K. (2015). High-intensity stepwise conditioning program for improved exercise responses and agility performance of a badminton player with knee pain. Physical Therapy in Sport, 16(1), 80-85.

Coso, J. D., Estevez, E., Baquero, R.A., \&Mora-Rodriguez, R. (2008). Anaerobic Performance when rehydrating with water or commercially available sport drinks during prolonged exercise in the heat. Appl Physiol Nutr Metab, 33, 290-298.

Fahlström, M., Fahlström, P. G., \&Lorentzon, R. (2006). Positive short-term subjective effect of sports drink supplementation during recovery. J Sports Med Phys Fitness, 46, 57884.

Gaieny, A., SattariFard, S., \& Rezaie, V. (2012). Short-term effects of two energy drinks on anaerobic power athlete female students. Journal of Applied Research in Sport Management and Life Sciences, 1(1), 69-74.

Global Sports Drinks Report Comprehensive Analysis of Trends in the Global Sports Drinks Market Including Long-term Forecasts, 2014. Retrieved from http://www.reportlinker.com.

Hamouti, N., Fernández-Elías, V. E., Ortega, J. F., \& Mora-Rodriguez, R. (2014). Ingestion of sodium plus water improves cardiovascular function and performance during dehydrating cycling in the heat. Scand J Med Sci Sports.; 24(3), 507-18.

Kazemi, F., Gaieny, A., \&Kordi, M. R. (2010). The effects of energy drinks on some cardiovascular parameters female student-athlete. Journal of Sport Biosciences, 7, 517. 
Kumar, G., Park, S., Onufrak, S. (2015). Perceptions about energy drinks are associated with energy drink intake among U.S. youth.Am J Health Promot, 29(4):238-44.doi: 10.4278/ajhp.130820-QUAN-435. Epub 2014 Jan 24. PMID: 24460002

Labotz, M., Harris, S. S., \& Anderson, J. (2009). Care of the Young Athlete. American Academy of Pediatrics, 3, 71-80.

Larson, N.,DeWolfe, J., Story, M., \&Neumark-Sztainer, D. (2014). Adolescent consumption of sports and energy drinks: Linkages to higher physical activity, unhealthy beverage patterns, cigarette smoking, and screen media use, Journal of Nutrition Education and Behavior, 46(3), 181-187.

Logan-Sprenger, H. M., Heigenhauser, G. J., Jones, G. L., \&Spriet, L. L. (2015). The effect of dehydration on muscle metabolism and time trial performance during prolonged cycling in males, Physiol Rep, 3(8). pii: e12483.

Neal, R.A., Corbett, J., Massey, H. C., \&Tipton, M.J. (2015). Effect of short-term heat acclimation with permissive dehydration on thermoregulation and temperate exercise performance, Scand J Med Sci Sports, 6(8),875-84. doi: 10.1111/sms. 12526.

Peltier, S. L., Leprêtre, P. M., Metz, L., Ennequin, G., Aubineau, N., Lescuyer, J. F., ...Sirvent, P. (2013). Effects of pre-exercise, endurance, and recovery designer sports drinks on performance during tennis tournament simulation. J Strength Cond Res, 27(11), 3076-83.

Pérez-Idárraga, A., \& Aragón-Vargas, L. F. (2014). Postexercise rehydration: potassium-rich drinks versus water and a sports drink. ApplPhysiolNutrMetab, 39(10):1167-1174. doi: 10.1139/apnm-2013-0434.

Samavati Sharif, M., Hojatti, S., Vojdani., S., \& KashrafiFard, S. (2013). Study the effect of menstrual cycle and consumption of $6 \%$ carbohydrate beverages on the maximal physical activity of active women. Journal of Hamadan University of Medical Sciences \& Health Services, 20(4).

Urdampilleta, A., Gómez-Zorita, S., Soriano, J. M., Martínez-Sanz, J. M., Medina, S., \& GilIzquierdo, A. (2015). Hydration and chemical ingredients in sport drinks: food safety in the European context, NutrHosp, 31(5), 1889-1899.

Zytnick, D., Park, S., \&Onufrak S. J. (2015). Child and caregiver attitudes about sports drinks and weekly sports drink intake among U.S. youth, Am J Health Promot, 30(3), e1109. doi: 10.4278/ajhp.140103-QUAN-8. 